\title{
Apical sodium-glucose co-transport can be regulated by blood-borne glucose in the ruminal epithelium of sheep (Ovis aries, Merino breed)
}

\author{
Cengiz Atasoglu ${ }^{1,2}$, Gotthold Gäbel ${ }^{1}$ and Jörg R. Aschenbach ${ }^{1 *}$ \\ ${ }^{1}$ Institute of Veterinary Physiology, Leipzig University, An den Tierkliniken 7, D-04103 Leipzig, Germany \\ ${ }^{2}$ Canakkale Onsekiz Mart University, Faculty of Agriculture, Department of Animal Science, 17100 Canakkale, Turkey
}

(Received 10 February 2004 - Revised 16 June 2004 - Accepted 22 July 2004)

\begin{abstract}
The intestinal Na-dependent D-glucose co-transporter (SGLT)-1 in sheep is under dietary regulation by luminal substrates. The aim of the present study was to find out whether the SGLT-1 in the forestomach of sheep is also regulated by sugars. Furthermore, the location of a possible glucosensor (luminal $v$. intracellular $v$. basolateral) was to be elucidated. Ruminal epithelia of sheep (Ovis aries, Merino breed) were pre-incubated in Ussing chambers with various substrates on the mucosal (i.e. luminal) or serosal (i.e. blood) side. This pre-incubation period was followed by a second pre-incubation period without the tested substrates (washout period). Thereafter, apical D-glucose uptake by ruminal epithelial cells was determined with $200 \mu \mathrm{mol} \mathrm{D}-\left[{ }^{14} \mathrm{C}\right]$ glucose/l in the absence or co-presence of the SGLT-1 inhibitor, phlorizin. Pre-incubation with D-glucose on the mucosal side had no significant effect on apical D-glucose uptake $(P>0 \cdot 05)$. In contrast, pre-incubation with D-glucose, D-mannose, 3- $O$-methyl-D-glucose or sucrose on the serosal side significantly increased D-glucose uptake compared with mannitol-treated controls $(P<0.05)$. Serosal pre-incubation with cellobiose or D-xylose had no effect. The stimulation of D-glucose uptake by serosal D-glucose pre-incubation was concentration dependent, with maximal stimulation at about $10 \mathrm{mmol} / \mathrm{l}$. We conclude that the ruminal SGLT-1 can be up-regulated in a concentration-dependent manner by blood-borne D-glucose via an extracellular sugar-sensing mechanism.
\end{abstract}

Sodium-glucose-linked transport: Glucosensor: Rumen: Sheep

Adult ruminant animals achieve their energy demand largely by the absorption of SCFA from their forestomachs, especially from the rumen (Gäbel et al. 2002). The SCFA, in turn, are derived from fermentation of carbohydrates by the microbes in the rumen. Given the extensive carbohydrate fermentation, absorption of glucose has long been thought to be of no significance to the ruminant animal (Merchen, 1988; Britton \& Krehbiel, 1993). However, recent studies have clearly demonstrated on molecular and functional levels that glucose can be taken up from the rumen of sheep and fallow deer (Cervus dama) via the sodium-glucose-linked transporter (SGLT)-1 (Aschenbach et al. 2000a,b, 2002b). SGLT-1, in turn, has been known for a long time to be the key absorptive mechanism for D-glucose in the intestine (Wright, 1993; Wood \& Trayhurn, 2003).

The ruminal SGLT-1 of sheep is sensitive to hormonal regulation by adrenaline (Aschenbach et al. 2002a) similarly to the intestinal SGLT-1 of rats (Ishikawa et al. 1997). However, very little is known about a possible substrate regulation of SGLT-1 in ruminal epithelial cells. Substrate regulation of SGLT-1 has been well documented in the intestinal epithelium of sheep (Bauer et al. 1995;
Shirazi-Beechey et al. 1995). The activity and expression of the intestinal SGLT-1 declines dramatically when the pre-ruminant lamb is weaned and matures, in parallel to a significant decrease in the levels of luminal monosaccharides entering the small intestine (Wood et al. 2000). The activity of the ovine intestinal SGLT-1 can be reconstituted by luminal, but not intravenous, infusion of glucose, suggesting direct dietary regulation (Shirazi-Beechey et al. 1994).

Possible substrate regulation of the ovine ruminal SGLT-1 was recently indicated by a decreased transport of the glucose analogue, 3- $O$-methyl-D-glucose, after $48 \mathrm{~h}$ food deprivation (Gäbel \& Aschenbach, 2002). However, it remained unclear whether this was a specific effect attributable to the absence of carbohydrates. In addition, an up-regulation of SGLT-1 by energy-rich diets would be much more important for the productivity and wellbeing of the animal than down-regulation during starvation (Aschenbach et al. 2000a, 2002a). The present study was, therefore, intended to find out whether up-regulation of the ruminal SGLT-1 can be induced by D-glucose or other sugars and whether this occurs in a way similar to that observed in the small intestine of sheep.

\footnotetext{
Abbreviations: $I_{\mathrm{sc}}$, short-circuit current; SGLT, sodium-dependent D-glucose co-transporter.

* Corresponding author: Dr J. R. Aschenbach, fax +49 34197 38097, email aschenb@rz.uni-leipzig.de
} 


\section{Materials and methods}

Animals and preparation of epithelia

Adult (2-5 years old) female sheep (Ovis aries, Merino breed) were fed good-quality meadow hay (first cut), and mineral blocks and water ad libitum for at least $14 \mathrm{~d}$ before the experiments. Sheep were stunned by bolt pistol and killed by exsanguination. The gastrointestinal tract was removed immediately from the abdominal cavity. Stripped ruminal epithelia were prepared from the ventral ruminal sac and mounted into Ussing chambers. Epithelial preparations were incubated with $15 \mathrm{ml}$ buffer solution on their mucosal (luminal) and serosal (blood) sides under short-circuit conditions as described by Aschenbach et al. (2000b). Experiments were in accordance with the German legislation on the protection of animals and were communicated to the Regierungspräsidium Leipzig (AZ 74-9162.11-01-T53/01).

\section{Buffer solutions}

Buffer solutions used for washing, transport and incubation of epithelia contained (mmol/l): $\mathrm{NaCl} 75, \mathrm{KCl} \mathrm{5,} \mathrm{CaCl}_{2} 1$, $\mathrm{MgCl}_{2}$ 1, $\mathrm{NaH}_{2} \mathrm{PO}_{4} 1, \mathrm{Na}_{2} \mathrm{HPO}_{4}$ 2, L-glutamine 1, sodium acetate 10 , sodium propionate 10 , butyric acid 10 , sodiumDL-lactate 5, HEPES (free acid) 10, mannitol 40, NaOH (283-293 mosmol/kg, pH 7.36-7.44) 10. Solutions were gassed with $100 \% \mathrm{O}_{2}$ at $37^{\circ} \mathrm{C}$.

\section{Pre-incubation of epithelia with different substrates}

Ruminal epithelia were pre-incubated with D-mannitol (control) or D-glucose, D-mannose, 3- $O$-methyl-D-glucose, sucrose, cellobiose or D-xylose at a concentration of $10 \mathrm{mmol} / \mathrm{l}$ on the mucosal or serosal side for 10 or $240 \mathrm{~min}$. Some epithelia were pre-incubated with increasing concentrations of D-glucose $(0 \cdot 0-17.8 \mathrm{mmol} / \mathrm{l})$ on the serosal side for $10 \mathrm{~min}$. Transepithelial osmotic gradients and differences in osmolarity between treatments were avoided by compensatory mannitol additions. The preincubation period with substrates was followed by a second $10 \mathrm{~min}$ pre-incubation period without any of the substrates (washout period).

\section{Glucose uptake technique}

The glucose uptake technique for ruminal epithelia has been described in detail previously (Aschenbach et al. 2002a). Briefly, $200 \mu \mathrm{mol}$ D-glucose/l spiked with $80 \cdot 1 \mu \mathrm{Ci} \mathrm{D}-\left[{ }^{14} \mathrm{C}\right]$ glucose/l were added to the mucosal side for $1 \mathrm{~min}$. After three washings, the mucosal area previously exposed to the uptake buffer was covered with $4 \mathrm{ml}$ ice-cold $\mathrm{NaOH}(100 \mathrm{mmol} / \mathrm{l})$ for $3 \mathrm{~min}$ in a selfmade lysing device. Cornified aggregates were removed from the harvested lysate by centrifugation (3000 $\mathrm{g}$, $15 \mathrm{~min})$. The D-glucose and protein contents of lysates were determined in duplicate by scintillation counting and method of Smith et al. (1985) respectively.

Pairs of epithelia were incubated in the absence or the mucosal presence of the inhibitor of SGLT-1, phlorizin $(100 \mu \mathrm{mol} / \mathrm{l})$. The decrease in $\mathrm{D}$-glucose uptake induced by phlorizin (i.e. phlorizin-sensitive D-glucose uptake) can be interpreted as the portion of D-glucose uptake attributable to SGLT-1. Phlorizin was dissolved in ethanol. Corresponding epithelia without phlorizin received an equivalent amount of ethanol.

\section{Electrophysiological measurements}

Experiments were conducted in the absence of electrochemical gradients, i.e. with buffer of the same composition on both sides of the epithelium and the transepithelial potential difference clamped to $0 \mathrm{mV}$ (short-circuit conditions). Tissue conductance and short-circuit current $\left(I_{\mathrm{sc}}\right)$ were monitored continuously, as explained in detail by Aschenbach et al. $(2000 b)$. The $I_{\mathrm{sc}}$ is equivalent to the net charge transfer across the epithelium. To compare the effect of different substrates on $I_{\mathrm{sc}}$, the increase in $I_{\mathrm{sc}}$ was calculated between the time points immediately before substrate additions and the time points immediately before washout (i.e. 10 or $240 \mathrm{~min}$ thereafter). The allotment of epithelia to different substrate treatments was based on their tissue conductance values about $30 \mathrm{~min}$ after mounting. Care was taken to have low- and high-conductance epithelia represented equally in all groups. Pairs of epithelial tissues used for determination of phlorizinsensitive uptake were not allowed to differ in their conductance values by $>25 \%$.

\section{Statistical analyses}

Arithmetic mean values are presented with their standard errors. Statistical differences were established by one-way or two-way repeated measurements ANOVA (normal distribution) or repeated measurements ANOVA on ranks (no normal distribution). Following ANOVA, groups that differed were isolated by the multiple comparison procedures of Student-Newman-Keul or Dunnett.

\section{Chemicals}

$\mathrm{O}_{2}$ was supplied by Messer Griesheim (Krefeld, Germany). $\mathrm{D}-\left[\mathrm{U}-{ }^{14} \mathrm{C}\right]$ Glucose was purchased from Amersham Pharmacia Biotech (Freiburg, Germany). The scintillation fluid, Aquasafe 300 Plus, was purchased from Zinsser Analytic (Maidenhead, Berks., UK). All other chemicals were supplied by either Merck (Darmstadt, Germany) or Sigma-Aldrich (Deisenhofen, Germany).

\section{Results}

Apical uptake of D-glucose was 56.1 (SEM 7.2) pmol/mg protein per min after control pre-incubation with D-mannitol on both sides. This basal uptake was reduced $(P<0 \cdot 01)$ to 36.0 (SEM 5.8) $\mathrm{pmol} / \mathrm{mg}$ protein per min after inhibition of SGLT-1 by mucosal addition of phlorizin. Consequently, phlorizin-sensitive apical uptake of D-glucose was $20 \cdot 1$ (SEM 6.3) $\mathrm{pmol} / \mathrm{mg}$ protein per min under control conditions. Pre-incubation of ruminal epithelia with D-glucose on the mucosal side did not result in a significant increase of phlorizin-sensitive D-glucose uptake (Expt 1 in Table 1). On the other hand, phlorizin-sensitive apical 
uptake of D-glucose was more than doubled by pre-incubation with $\mathrm{D}$-glucose on the serosal side $(P<0.05)$. A comparable increase in phlorizin-sensitive uptake of D-glucose was induced by serosal pre-incubation with mannose $(P<0.05$; Expt 1 in Table 1$)$.

The effectiveness of serosal D-glucose and D-mannose in increasing D-glucose uptake within only $20 \mathrm{~min}$ (i.e. $10 \mathrm{~min}$ pre-incubation +10 min washout) indicated that genomic effects are most probably not involved. To substantiate this hypothesis, we tested whether an increase in pre-incubation time would further increase the stimulation of phlorizin-sensitive uptake by serosal D-glucose or D-mannose. However, phlorizin-sensitive apical uptake of D-glucose did not increase any further when increasing the pre-incubation time (with serosal D-glucose or D-mannose) from 10 to 240 min (Fig. 1(A)). Furthermore, a 240 min pre-incubation with D-glucose on the mucosal side was as ineffective in increasing $\mathrm{D}$-glucose uptake as in a 10 -min pre-incubation (Fig. 1(A)).

It was shown in a previous study that D-glucose application to ruminal epithelia induced an increase in $I_{\mathrm{sc}}$ that could be attributed partly (mucosal application) or completely (serosal application) to intracellular metabolism of D-glucose (Aschenbach et al. 2002b). Similarly, serosal mannose can be metabolized by the ruminal epithelial cells and thus increases $I_{\mathrm{sc}}$ (Aschenbach et al. 2000b). Therefore, the increase in $I_{\mathrm{sc}}$ within the period of substrate pre-incubation $\left(\Delta I_{\mathrm{sc}}\right)$ was analysed to elucidate a possible link between hexose metabolism and the observed stimulation of phlorizin-sensitive D-glucose uptake. In comparison with control pre-incubations, the application of D-glucose or D-mannose $(10 \mathrm{mmol} / \mathrm{l})$ induced a moderate to marked $\Delta I_{\mathrm{sc}}(P<0.05$; Expt 1 in Table 1; Fig. 1(B)). Serosal addition of D-glucose or D-mannose was more effective in increasing $I_{\mathrm{sc}}$ than mucosal addition of D-glucose $(P<0.05)$. The $\Delta I_{\mathrm{sc}}$ values were not different with the 10 or $240 \mathrm{~min}$ pre-incubation protocol (Fig. 1(B)).

The effectiveness of serosal D-glucose in increasing apical D-glucose uptake and $I_{\mathrm{sc}}$ was dependent on the concentration of D-glucose during serosal pre-incubation. Both apical D-glucose uptake and $\Delta I_{\mathrm{sc}}$ increased almost in parallel during $10 \mathrm{~min}$ pre-incubations with $0.0-8.9 \mathrm{mmol} \mathrm{D}$-glucose $/ \mathrm{l}$ on the serosal side $(P<0.05$; FIg. 2).

The results described so far pointed to the possibility that serosally applied substrates could stimulate apical Dglucose uptake via the supply of metabolic energy. To test this hypothesis, ruminal epithelia were pre-incubated with the non-metabolisable D-glucose analogue, 3- $O$ methyl-D-glucose, two disaccharides (sucrose or cellobiose) and a pentose sugar (D-xylose) on the serosal side. None of these carbohydrates induced changes in $I_{\mathrm{sc}}$ at a concentration of $10 \mathrm{mmol} / \mathrm{l}$ (Table 2; Expts 5 and 6 in Table 1). After pre-incubation with non-metabolisable but cell-permeant 3-O-methyl-D-glucose, only total apical uptake of D-glucose was measured, which increased above mannitol-treated controls $(P<0 \cdot 05$; Table 2). Furthermore, an increase in phlorizin-sensitive uptake of Dglucose could be established for cell-impermeant sucrose, whereas cellobiose or D-xylose had no effect (Table 1).

\section{Discussion}

Several previous studies have suggested that the basolateral pole is the dominant site of D-glucose entry into ruminal epithelial cells in the living animal (Remond et al. 1993; Lozano et al. 2000). Following basolateral entry via a yet unidentified isoform of GLUT (Aschenbach et al. 2000b), D-glucose is metabolised to lactate or, to a much lesser extent, totally oxidised to $\mathrm{CO}_{2}$ (Baldwin \& McLeod,

Table 1. Effect of different 10 min pre-incubations with substrates on phlorizin-sensitive apical uptake of D-glucose and on the increase in short-circuit current $\left(\Delta I_{\mathrm{sc}}\right)$ within $10 \mathrm{~min}$ after substrate applications in isolated ruminal epithelia of sheep*

(Mean values with their standard errors)

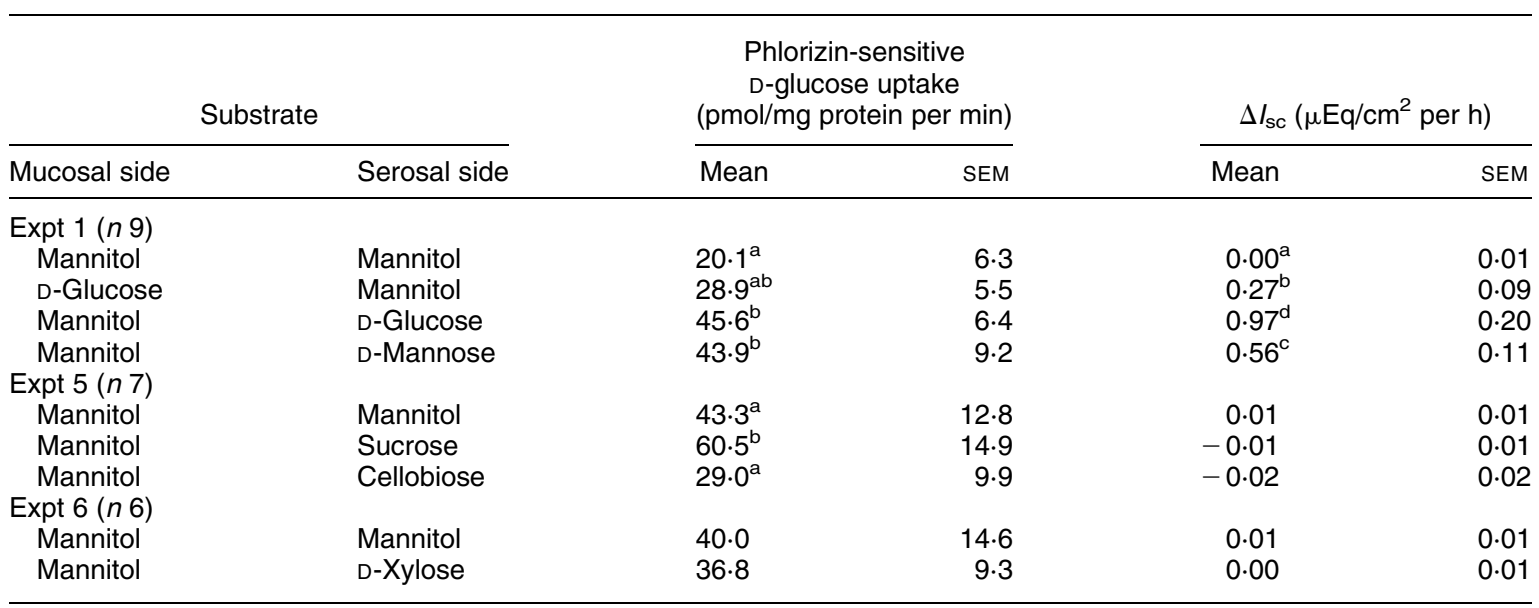

a,b,c,d For each experiment, mean values within a column with unlike superscript letters were significantly different $(P<0.05)$.

* The ruminal epithelia were pre-incubated either bilaterally with $10 \mathrm{mmol} \mathrm{D}$-mannitol/I or on one side with the indicated substrate (10 mmol/I) for $10 \mathrm{~min}$, followed by a further pre-incubation period in substrate-free buffer for $10 \mathrm{~min}$ before a 1 min glucose uptake period. Phlorizinsensitive D-glucose uptake was calculated for each animal as the difference between the uptakes in the absence and presence of phlorizin $(100 \mu \mathrm{mol} / \mathrm{l})$. For details of procedures, see p. 778. 

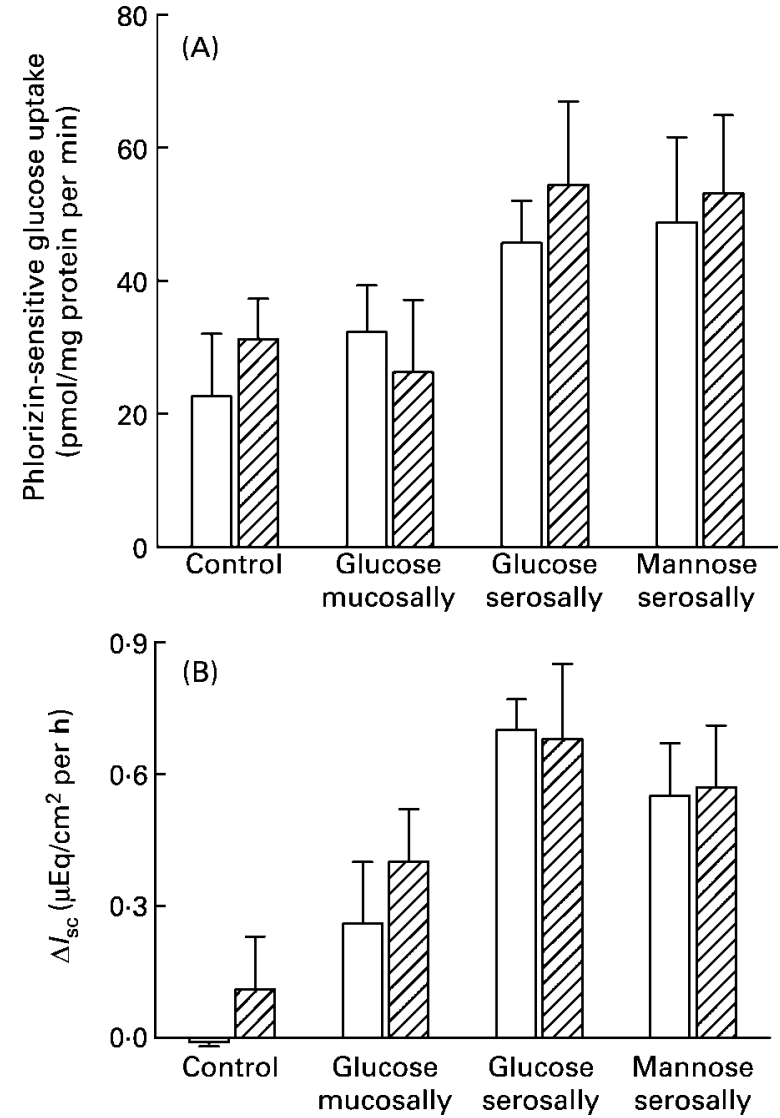

Fig. 1. Effect of pre-incubation with $10 \mathrm{mmol} / \mathrm{l}$-D-glucose or $10 \mathrm{~mm}$ D-mannose for 10 or $240 \mathrm{~min}$ on phlorizin-sensitive D-glucose uptake (A) and on increases in short-circuit current $\left(I_{\mathrm{sc}}\right)(\mathrm{B})$ during the 10 $(\square)$ or $240(\mathbb{Q})$ min of substrate presence in isolated ruminal epithelia of sheep. For details of procedures, see p. 778. Uptake was measured at a concentration of $200 \mu \mathrm{mol} / \mathrm{l}-\mathrm{D}$-glucose after washing out the pre-incubation substrate for $10 \mathrm{~min}$. On two-way repeated measurements ANOVA, D-glucose uptakes and $I_{\mathrm{sc}}$ were increased equally by serosal pre-incubations with $\mathrm{D}$-glucose or D-mannose $(P<0.05)$. Mucosal pre-incubation with $\mathrm{D}$-glucose had no effect on D-glucose uptake but increased $I_{\text {sc }}$ to values below those after serosal D-glucose or D-mannose pre-treatment $(P<0.05)$. The time of substrate presence had no effect on glucose uptake or $I_{\text {sc }}$. Values are means with their standard errors shown by vertical bars $(n 6)$.

2000). The basolateral uptake and metabolism of D-glucose can be visualised by an increase in $I_{\mathrm{sc}}$ in Ussing-chambered ruminal epithelia (Aschenbach et al. 2000b, 2002b). The relative contribution of $\mathrm{D}$-glucose to the epithelial cell

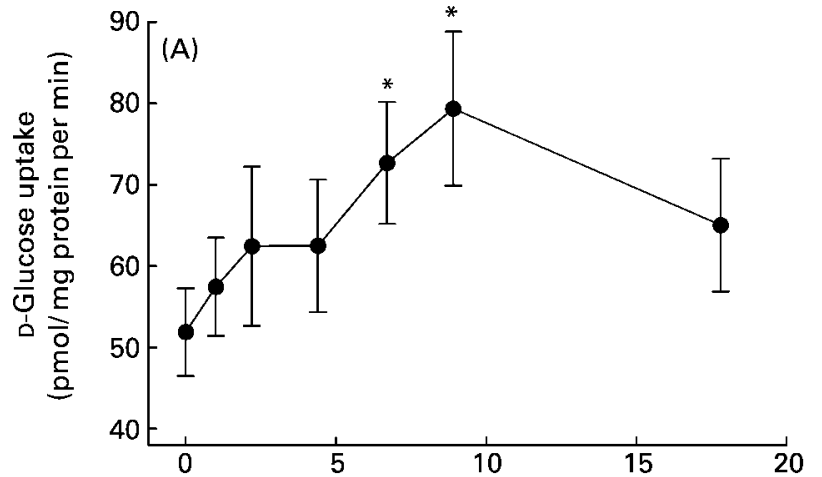

D-Glucose concentration during pre-incubation $(\mathrm{mmol} / \mathrm{l})$

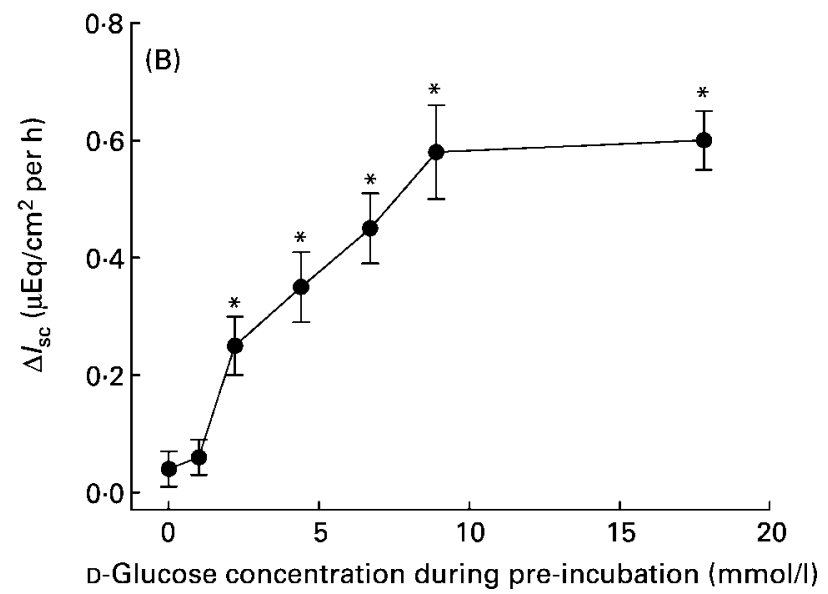

Fig. 2. Influence of $D$-glucose concentration on the serosal side (A) on apical D-glucose uptake and $(B)$ on short-circuit current $\left(I_{\mathrm{sc}}\right)$ in isolated ruminal epithelia of sheep. For details of procedures, see p. 778. The ruminal epithelia were pre-incubated with increasing concentrations of $D$-glucose on the serosal side for $10 \mathrm{~min}$, followed by a further pre-incubation period in D-glucose-free buffer for $10 \mathrm{~min}$ before a 1 min $D$-glucose uptake period. Values are means with their standard errors shown by vertical bars $(n 9)$. Mean values were significantly different from the control values $(0 \mathrm{mmol} / \mathrm{l})$ : ${ }^{*} P<0.05$.

energy requirement, however, is less than that of the SCFA taken up from the lumen (Baldwin \& McLeod, 2000). Thus, the net disappearance of D-glucose from blood into the ruminal wall is not very high. It amounts to only 6$12 \mathrm{mmol} / \mathrm{d}$ in adult sheep on a hay-based diet, which is approximately ten times less than mesenteric glucose disappearance (Remond et al. 1993; Han et al. 2002).

Table 2. Effect of a serosal 10 min pre-incubation with 3-O-methyl- $\alpha$-D-glucose (3-OMG) on apical uptake of D-glucose and on the increase in short-circuit current $\left(\Delta I_{\mathrm{sc}}\right)$ in isolated ruminal epithelia of sheep*

(Mean values with their standard errors)

\begin{tabular}{|c|c|c|c|c|c|}
\hline \multicolumn{2}{|c|}{ Substrate } & \multicolumn{2}{|c|}{$\begin{array}{c}\text { D-glucose uptake } \\
\text { (pmol/mg protein per min) }\end{array}$} & \multicolumn{2}{|c|}{$\Delta I_{\mathrm{sc}}\left(\mu \mathrm{Eq} / \mathrm{cm}^{2}\right.$ per $\left.\mathrm{h}\right)$} \\
\hline Mucosal side & Serosal side & Mean & SEM & Mean & SEM \\
\hline \multicolumn{6}{|l|}{ Expt $4(n 7)$} \\
\hline Mannitol & Mannitol & $55 \cdot 8^{a}$ & $6 \cdot 5$ & -0.01 & 0.01 \\
\hline Mannitol & 3-OMG & $85.9^{b}$ & $8 \cdot 6$ & 0.00 & 0.00 \\
\hline
\end{tabular}


The extent to which the basolateral net flux of D-glucose is complemented or affected by an apical uptake from the ruminal content has not been measured directly. Intra-ruminal concentrations of glucose appear to be very low, because it is rapidly converted to SCFA and lactic acid by ruminal bacteria (Russell \& Gahr, 2000). However, periods with appreciable glucose concentrations can be expected with diets containing either large amounts of glucose itself or large amounts of other very easily fermentable carbohydrates (Kajikawa et al. 1997). Such concentrate diets are being used increasingly to enhance the performance of ruminant animal production, especially milk yield in cattle (Gäbel et al. 2002). We have suggested that glucose absorption from the rumen occurs under these circumstances and is advantageous. Apart from some energetic benefits, it would contribute to decreased luminal glucose availability and thus decrease the risk of ruminal lactic acidosis, a disorder caused by excessive acid release from bacterial fermentation (Aschenbach et al. 2000a, 2002a).

Absorption of D-glucose from the rumen of sheep depends on its Na-dependent uptake across the apical cell membrane via SGLT-1 (Aschenbach et al. 2000a,b, 2002a). The capacity of the Na-dependent uptake was previously assessed in the antibiotic-treated reticulorumen of sheep in vivo (Aschenbach et al. 2000a). At a concentration of $0.50 \mathrm{mmol} \mathrm{D}$-glucose $/ 1,0.07 \mathrm{mmol} \mathrm{D}$-glucose was extracted from each litre of an intra-ruminal solution within $1 \mathrm{~h}$ (i.e. $13 \% / \mathrm{h}$ ). Because the concentration of $0.50 \mathrm{mmol} / \mathrm{l}$ was well above the concentration of half-maximal D-glucose transport by SGLT-1 $\left(K_{0.5} 0 \cdot 28\right.$; Aschenbach et al. $\left.2000 b\right)$, it was initially assumed that D-glucose absorption would not rise much further at higher D-glucose concentrations. However, in the same study, D-glucose disappearance rate from the reticulorumen amounted to $2.90 \mathrm{mmol} /(\mathrm{l} \cdot \mathrm{h})$ at a concentration of $12.00 \mathrm{mmol} / \mathrm{l}$ (i.e. $24 \% / \mathrm{h}$; Aschenbach et al. $2000 a$ ). This is quite a remarkable value compared with the net glucose disappearance from blood cited earlier (Remond et al. 1993; Han et al. 2002). On the other hand, the sharp increase in glucose absorption between luminal concentrations of 0.50 and $12.00 \mathrm{mmol} / \mathrm{l}$ can only be explained by some kind of substrate regulation of SGLT-1. Accordingly, ruminal SGLT-1 activity decreased in another study after $48 \mathrm{~h}$ feed deprivation (Gäbel \& Aschenbach, 2002). The presence and characteristics of possible substrate regulation were addressed in the present study.

Our present results demonstrate that apical phlorizinsensitive D-glucose uptake by ruminal epithelia is stimulated by D-glucose presence on the serosal, i.e. blood, side (Fig. 1(A)). This is in contrast to the intestine, where substrate regulation of SGLT-1 is mainly attributed to the availability of substrates in the intestinal lumen (Shirazi-Beechey et al. 1991; Shirazi-Beechey, 1996; Dyer et al. 1997). Nevertheless, the effects of sugars on SGLT-1 per se may bear similarities apart from the different location of glucosensors in the rumen $v$. intestine. Concerning the intestine, it is known that the luminal glucosensor has a broad substrate specificity, is located on the external face of cells and operates independently from D-glucose or other substrate metabolism (Dyer et al. 2003). All these characteristics apply also to the blood-side-directed glucosensor in the ruminal epithelium: the ruminal SGLT-1 can be stimulated by glucose itself as well as by other sugars. Among the stimulating sugars were those that are transported by apical SGLT-1 as well as basolateral GLUT (D-glucose, 3-O-methyl-glucose), those that are transported by GLUT but poorly or not by SGLT-1 (D-mannose) and those that are transported by neither GLUT nor SGLT-1 (sucrose). In this regard, the efficacy of sucrose in stimulating SGLT-1 also proves that the D-glucose sensor has an extracellular location because sucrose as a disaccharide is almost membrane impermeant and cannot accumulate inside the cells. It can be excluded that the effect of sucrose involved extracellular sucrose hydrolysis (to give D-glucose). Such indirect action of sucrose via D-glucose would have been recognisable by a rise in $I_{\mathrm{sc}}$, which was absent. The rise in $I_{\mathrm{sc}}$ due to D-glucose can be attributed to its intracellular metabolism after basolateral uptake via GLUT (Aschenbach et al. 2000b, 2002b). A similar metabolic effect was seen with D-mannose but not 3-O-methyl-glucose or sucrose. Therefore, metabolism of substrates is not essential for the stimulation of the ruminal SGLT-1.

It has been proven for the intestine that the signalling pathway of the glucosensor involves generation of cAMP and activation of protein kinase A (Dyer et al. 2003). It is conceivable that the same pathway is used in the ruminal epithelium. We have shown previously that experimental stimulation of cAMP generation by forskolin can increase the activity of the ruminal SGLT-1 (Aschenbach et al. $2002 a$ ). However, both the increase in SGLT-1 activity induced by forskolin (Aschenbach et al. 2002a) and the substrate regulation of SGLT-1 (present study) occur rather rapidly in the ruminal epithelium (from $\mathrm{s}$ to $\mathrm{min}$ ). The rapid onset of substrate-induced increases in SGLT-1 activity is in contrast to observations in the intestine and strongly suggests that the regulation in the ruminal epithelium is not transcriptional. With regulation of SGLT-1 at the mRNA or protein expression level, one would have expected a slower response or, at least, a fortification of the stimulatory effect when increasing the pre-incubation time with substrates towards several hours. The latter was not obvious (Fig. 1).

Increases in plasma glucose levels have previously been implicated in enhanced functional activity of the intestinal SGLT-1 during diabetes. However, the blood-side regulation of the ruminal SGLT-1 in the present study appears to be different from that described earlier in diabetic rats (Debnam, 1994). This effect in diabetic rats has been attributed to an increased $\mathrm{Na}^{+}$driving force due to a decrease in apical membrane $\mathrm{Na}^{+}$conductance (Debnam, 1994; Sharp et al. 1997). However, the increased net absorption of positive charges $\left(I_{\mathrm{sc}}\right)$ after serosal D-glucose application in the present study supports an increased electrogenic $\mathrm{Na}^{+}$transfer across the apical membrane rather than a decrease. In addition, blood-side regulation in the rat intestine seems more strictly bound to D-glucose and not to other substrates (Sharp \& Debnam, 1994). An effect of diabetes on SGLT-1 has also been described in human subjects, namely an increase in the mRNA and protein expression of SGLT-1. However, the subjects of the human study had been on hypoglycaemic treatment, 
which could indicate an influence of diabetes on SGLT-1 expression even in the absence of hyperglycaemia (Dyer et al. 2002). In contrast, a specific effect of basolateral D-glucose on SGLT-1 function was investigated and established in the present study. It turns out that substrate stimulation of the ruminal SGLT-1 by blood-borne D-glucose could present a new regulatory principle, which seems related to the regulation of the intestinal SGLT-1 by luminal substrates.

The blood-side stimulation of the ruminal SGLT-1 was dose-dependent in the range of potential plasma glucose concentrations (Fig. 2(A)), suggesting a physiological role in the living animal. The plasma glucose concentration of ruminant animals can be influenced by the diet. For example, sheep grazing on spring pasture have significantly greater plasma glucose concentrations than the same animals on autumn pasture $(4.8$ v. $3.6 \mathrm{mmol} / \mathrm{l}$; Maas et al. 2001). These differences in blood glucose availability are mostly attributed to a changing supply of glucogenic substrates by ruminal bacteria (e.g. propionate) or to post-ruminal absorption of D-glucose (Merchen, 1988; Bauer et al. 1995; Russell \& Gahr, 2000). However, the different content of soluble carbohydrates in spring $v$. autumn grass (138 v. $77 \mathrm{~g} / \mathrm{kg} \mathrm{DM})$ presents an equally plausible explanation. Direct ruminal infusions of moderate amounts of D-glucose (about 3-4 g/ $\mathrm{kg}$ body weight) increase plasma glucose concentration of sheep from about 3 to $6 \mathrm{mmol} / \mathrm{l}$ if given as a bolus (Dougherty et al. 1956) or from 3.1 to $4.1 \mathrm{mmol} / \mathrm{l}$ if infused over $2 \mathrm{~h}$ (Giduck et al. 1988). The immediate increase after a bolus application (Dougherty et al. 1956) points to a significant contribution of forestomach glucose absorption to blood glucose availability under these conditions. However, with starch as a concentrate energy source, changes in plasma glucose concentrations are usually much more subtle (Swanson et al. 2000), as long as ruminal acidosis is not induced. Thus, different carbohydrates seem to contribute differently to plasma glucose availability. Non-nutritional factors that influence plasma glucose levels are animal species (e.g. deer > sheep; Webster et al. 1996; El-Sherif \& Assad, 2001), breed (lean $>$ fat genotype sheep; Francis et al. 1999) and reproductive stage (lactators $>$ non-lactators; El-Sherif \& Assad, 2001; Gow et al. 2003).

From a quantitative point of view, the blood-sidedirected glucosensor discovered in the present study explains only part of the stimulation observed previously in vivo (Aschenbach et al. 2000a). This suggests that it may be either amplified or complemented by other regulatory mechanisms in vivo. Some plausible suggestions for these additional mechanisms are hormonal and/or neuronal stimuli, or changes in epithelial blood supply. These possibilities will have to be addressed in future studies.

\section{Acknowledgements}

The analytical skills of Mrs Karin Nestler and the support of H. Fuhrmann and J. Gottschalk are gratefully acknowledged. This study was funded by the H. Wilhelm Schaumann Foundation. C. A. thanks the Alexander von Humboldt Foundation for a research fellowship.

\section{References}

Aschenbach JR, Bhatia SK, Pfannkuche H \& Gäbel G (2000a) Glucose is absorbed in a sodium-dependent manner from forestomach contents of sheep. J Nutr 13, 2797-2801.

Aschenbach JR, Wehning H, Kurze M, Schaberg E, Nieper H, Burckhardt G \& Gäbel G (2000b) Functional and molecular biological evidence of SGLT-1 in the ruminal epithelium of sheep. Am J Physiol 279, G20-G27.

Aschenbach JR, Borau T \& Gäbel G (2002a) Glucose uptake via SGLT-1 is stimulated by $\beta_{2}$-adrenoceptors in the ruminal epithelium of sheep. J Nutr 13, 1254-1257.

Aschenbach JR, Borau T \& Gäbel G (2002b) Sodium glucoselinked transport in the ruminal epithelium of fallow deer comparison to sheep. J Comp Physiol B 17, 561-567.

Baldwin RL \& McLeod KR (2000) Effects of diet forage:concentrate ratio and metabolizable energy intake on isolated rumen epithelial cell metabolism in vitro. J Anim Sci 78, $771-783$.

Bauer ML, Harmon DL, McLeod KR \& Huntington GB (1995) Adaptation to small intestinal starch assimilation and glucose transport in ruminants. J Anim Sci 73, 1828-1838.

Britton R \& Krehbiel C (1993) Nutrient metabolism by gut tissues. J Dairy Sci 76, 2125-2131.

Debnam ES (1994) Rapid adaptation of intestinal sugar transport. News Physiol Sci 9, 84-88.

Dougherty RW, Klavano CS, Dickson WM \& Klavano PA (1956) Blood sugar level in cattle and sheep fed various amounts of glucose. Cornell Vet 46, 397-409.

Dyer J, Barker PJ \& Shirazi-Beechey SP (1997) Nutrient regulation of the intestinal $\mathrm{Na}^{+}$/glucose co-transporter (SGLT1) gene expression. Biochem Biophys Res Commun 23, 624-629.

Dyer J, Vayro S, King TP \& Shirazi-Beechey SP (2003) Glucose sensing in the intestinal epithelium. Eur $J$ Biochem 27, 3377-3388.

Dyer J, Wood IS, Palejwala A \& Shirazi-Beechey SP (2002) Expression of monosaccharide transporters in intestine of diabetic humans. Am J Physiol 28, G241-G248.

El-Sherif MMA \& Assad F (2001) Changes in some blood constituents of Barki ewes during pregnancy and lactation under semi arid conditions. Small Rumin Res 40, 269-277.

Francis SM, Veenvliet BA, Littlejohn RP \& Suttie JM (1999) Plasma glucose and insulin levels in genetically lean and fat sheep. Gen Comp Endocrinol 11, 104-113.

Gäbel G \& Aschenbach JR (2002) Influence of food deprivation on the transport of 3-O-methyl-D-glucose across the isolated ruminal epithelium of sheep. J Anim Sci 80, 2740-2746.

Gäbel G, Aschenbach JR \& Müller F (2002) Transfer of energy substrates across the ruminal epithelium: implications and limitations. Anim Health Res Rev 3, 15-30.

Giduck SA, Fontenot JP \& Rahnema S (1988) Effect of ruminal infusion of glucose, volatile fatty acids and hydrochloric acid on mineral metabolism in sheep. $J$ Anim Sci 66, $532-542$.

Gow IF, Mitchell E \& Wait M (2003) Intravenous magnesium reduces the rate of glucose disposal in lactating sheep. Exp Physiol 88, 533-540.

Han XT, Noziere P, Remond D, Chabrot J \& Doreau M (2002) Effects of nutrient supply and dietary bulk on $\mathrm{O}_{2}$ uptake and nutrient net fluxes across rumen, mesenteric- and portal-drained viscera in ewes. J Anim Sci 80, 1362-1374.

Ishikawa Y, Eguchi T \& Ishida H (1997) Mechanism of $\beta$-adrenergic agonist-induced transmural transport of glucose in rat small intestine. Regulation of phosphorylation of SGLT1 controls the function. Biochim Biophys Acta 135, $306-318$ 
Kajikawa H, Amari M \& Masaki S (1997) Glucose transport by mixed ruminal bacteria from a cow. Appl Environ Microbiol 63, 1847-1851.

Lozano O, Theurer CB, Alio A, Huber JT, Delgado-Elorduy A, Cuneo P, DeYoung D, Sadik M \& Swingle RS (2000) Net absorption and hepatic metabolism of glucose, L-lactate, and volatile fatty acids by steers fed diets containing sorghum grain processed as dry-rolled or steam-flaked at different densities. J Anim Sci 78, 1364-1371.

Maas JA, Wilson GF, McCutcheon SN, Lynch GA, Burnham DL \& France J (2001) The effect of season and monensin sodium on the digestive characteristics of autumn and spring pasture fed to sheep. J Anim Sci 79, 1052-1058.

Merchen NR (1988) Digestion, absorption and excretion in ruminants. In The Ruminant Animal. Digestive Physiology and Nutrition, pp. 172-201 [DC Church, editor]. Englewood Cliffs, NJ: Prentice Hall.

Remond D, Chaise JP, Delval E \& Poncet C (1993) Net flux of metabolites across the ruminal wall of sheep fed twice a day with orchard grass hay. J Anim Sci 71, 2529-2538.

Russell RW \& Gahr SA (2000) Glucose availability and associated metabolism. In Farm Animal Metabolism and Nutrition, pp. 121-147 [JPF D'Mello, editor]. Wallingford, Oxon: CAB International.

Sharp PA, Boyer S, Srai SK, Baldwin SA \& Debnam ES (1997) Early diabetes-induced changes in rat jejunal glucose transport and the response to insulin. $J$ Endocrinol 15, $19-25$.

Sharp PA \& Debnam ES (1994) The effect of rapid changes in plasma sugar concentration on the brush-border potential difference in rat jejunum. Exp Physiol 79, 415-421.

Shirazi-Beechey SP (1996) Intestinal sodium-dependent D-glucose co-transporter: dietary regulation. Proc Nutr Soc 55, 167-178.

Shirazi-Beechey SP, Gribble SM, Wood IS, Tarpey PS,
Beechey RB, Dyer J, Scott D \& Barker PJ (1994) Dietary regulation of the intestinal sodium-dependent glucose cotransporter (SGLT1). Biochem Soc Trans 22, 655-658.

Shirazi-Beechey SP, Hirayama BA, Wang Y, Scott D, Smith MW \& Wright EM (1991) Ontogenic development of lamb intestinal sodium-glucose co-transporter is regulated by diet. $J$ Physiol 43, 699-708.

Shirazi-Beechey SP, Wood IS, Dyer J, Scott D \& King TP (1995) Intestinal sugar transport in ruminants. In Ruminant Physiology: Digestion, Metabolism, Growth and Reproduction, pp. 117-133 [WV Engelhardt, S Leonhard-Marek, G Breves and D Giesecke, editors]. Stuttgart: Enke Verlag.

Smith PK, Krohn RI, Hermanson GT, Mallia AK, Gartner FH, Provenzano MD, Fujimoto EK, Goeke NM, Olson BJ \& Klenk DC (1985) Measurement of protein using bicinchoninic acid. Anal Biochem 15, 76-85.

Swanson KC, Matthews JC, Matthews AD, Howell JA, Richards CJ \& Harmon DL (2000) Dietary carbohydrate source and energy intake influence the expression of pancreatic alpha-amylase in lambs. $J$ Nutr 13, 2157-2165.

Webster JR, Corson ID, Littlejohn RP, Stuart SK \& Suttie JM (1996) Effects of photoperiod on the cessation of growth during autumn in male red deer and growth hormone and insulin-like growth factor-I secretion. Gen Comp Endocrinol 11, 464-477.

Wood IS, Dyer J, Hofmann RR \& Shirazi-Beechey SP (2000) Expression of the $\mathrm{Na}^{+} /$glucose co-transporter (SGLT1) in the intestine of domestic and wild ruminants. Pflugers Arch 44, $155-162$.

Wood IS \& Trayhurn P (2003) Glucose transporters (GLUT and SGLT): expanded families of sugar transport proteins. Br J Nutr 89, 3-9.

Wright EM (1993) The intestinal $\mathrm{Na}^{+}$/glucose cotransporter. Annu Rev Physiol 55, 575-589. 